\title{
The quasi-two-day wave studied using the Northern Hemisphere SuperDARN HF radars
}

\author{
S. B. Malinga ${ }^{1, *}$ and J. M. Ruohoniemi ${ }^{2}$ \\ ${ }^{1}$ School of Physics, University of KwaZulu-Natal, Durban 4000, South Africa \\ ${ }^{2}$ The Johns Hopkins University Applied Physics Laboratory, Laurel, MD20723, USA \\ *now at: Hermanus Magnetic Observatory, PO Box 32, Hermanus, 7200, South Africa
}

Received: 15 November 2006 - Revised: 3 July 2007 - Accepted: 26 July 2007 - Published: 29 August 2007

\begin{abstract}
Data from the Super Dual Radar Network (SuperDARN) radars for 2002 were used to study the behaviour of the quasi-two-day wave (QTDW) in the Northern Hemisphere auroral zone. The period of the QTDW is observed to vary in the range of $\sim 42-56 \mathrm{~h}$, with the most dominant period being $\sim 48 \mathrm{~h}$ and secondary peaks at $\sim 42$ - and $\sim 52$-h. The spectral power shows a seasonal variation with a peak power (max 70) in summer. The power shows variations of several days and there is also evidence of changes in wave strength with longitude. The 42-h and the 48-h components tend to be strongly correlated in summer. The onset of enhanced wave activity tends to coincide with the westward acceleration of the zonal mean flow and occurs at a time of strong southward meridional flow. The most frequent instantaneous hourly period is in the 40 to $50 \mathrm{~h}$ period band, in line with the simultaneous dominance of the 42-h and the 48-h components. The wave numbers are less variable and are around -2 to -4 during times of strong wave activity. For a period of $\sim 48 \mathrm{~h}$, the zonal wave number is about -3 to -4 , using a negative value to indicate westward propagating waves. The 42 -h and the 52-h components cover a wider band in the -4 to 1 range. The wide zonal wave number spectrum in our results may account for the observed longitudinal variation in the spectral power of the wave.
\end{abstract}

Keywords. Meteorology and atmospheric dynamics (General circulation; Middle atmosphere dynamics; Waves and tides)

\section{Introduction}

The quasi-two-day wave (QTDW) is one of the strongest waves in the mesosphere and lower thermosphere (MLT) region. It was first studied in the late 1960s and early 1970s but

Correspondence to: S. B. Malinga

(smalinga@hmo.ac.za) the references below are made to more recent work. Over the years it has been studied by various ground-based instruments (e.g. Plumb et al., 1987; Jacobi et al., 1998; Gurubaran et al., 2001; Pancheva et al., 2004; Lima et al., 2004), satellite (e.g. Wu et al., 1993; Bristow et al., 1999) and through numerical simulations (e.g. Hagan et al., 1993; Merzlyakov and Jacobi, 2004; Jacobi et al., 2006). It is a globalscale wave that has been observed in both hemispheres and shows some seasonal behaviour with enhanced amplitudes in summer (e.g. Lima et al., 2004; Pancheva, 2006). However, in the equatorial region the enhancement tends to coincide with both solstices (Palo and Avery, 1996). The results of the equatorial sites of Christmas Island $\left(2^{\circ} \mathrm{N}\right)$ and Tirunelveli $\left(8.7^{\circ} \mathrm{N}\right)$, as reported by Palo and Avery (1996) and Gurubaran et al. (2001), respectively, show a stronger quasi-2-day wave in winter than in summer. Pancheva et al. (2004) found amplitude averages in the range $\sim 5-26 \mathrm{~m} / \mathrm{s}$ but peak amplitudes of $40 \mathrm{~m} / \mathrm{s}$ (Lima et al., 2004) and $90 \mathrm{~m} / \mathrm{s}$ (Pancheva, 2006) have also been reported. The amplitude of the QTDW have been observed to be modulated at $\sim 8-20$ days (Pancheva et al., 2004) and are also correlated to the solar cycle (Jacobi et al., 1997). At low- to mid-latitudes the meridional component is slightly stronger than its zonal counterpart, whereas at high latitudes the two components are comparable (Pancheva et al., 2004). Longitudinal studies (e.g. Thayaparan et al., 1997b; Pancheva et al., 2004) show that the wave is westward propagating with zonal wave numbers of $\sim 2-5$ depending on the period of the wave. The period of the QTDW is variable and ranges from about 43 to $53 \mathrm{~h}$ (Palo and Avery, 1996; Gurubaran et al., 2001; Pancheva et al., 2004). The period of this wave is also observed to vary with time (Pancheva et al., 2004) and this migration of the period with time is most likely connected to the net eastward acceleration in the zonal wind (Palo and Avery, 1996). Relatively low periods generally coincide with stronger wave activity (Jacobi et al., 1997). 


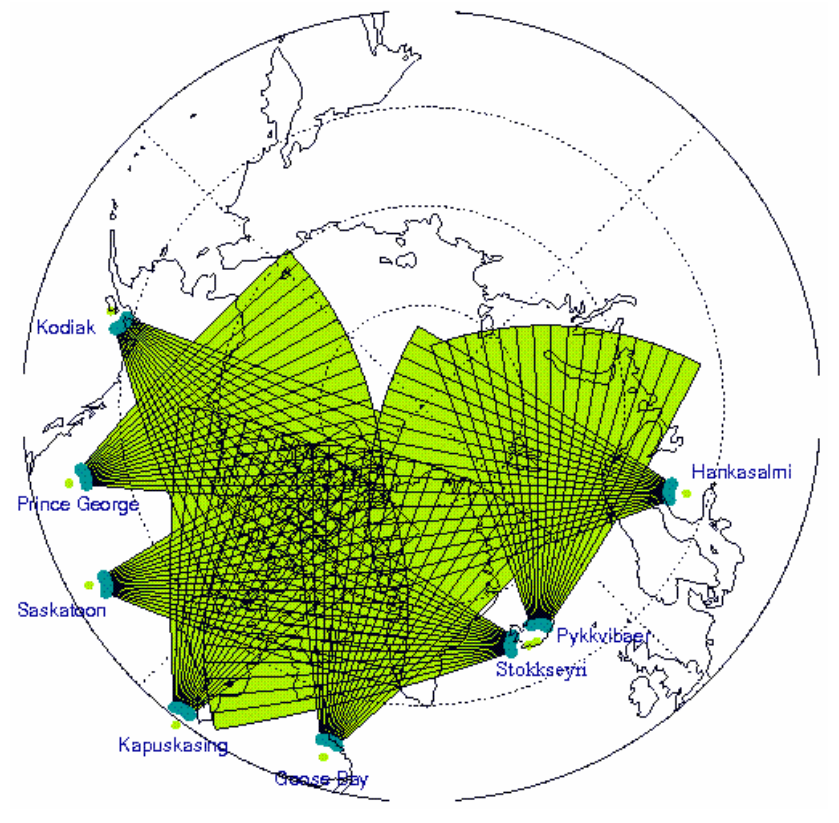

Fig. 1. The schematic diagram of the fields-of-view of the SuperDARN radars used in this paper. The inner range interval where the meteor echoes are detected is indicated by the overlapping dark green circles at the beginning of each radar field-of-view.

The QTDW interacts with various components of the atmosphere. For instance, it is reported to interact with the diurnal tide nonlinearly, as shown by an anticorrelation between the two waves, resulting in the production of secondary waves (Palo et al., 1999; Gurubaran et al., 2001; Pancheva, 2006). Jacobi et al. (1998) used a 14-year data set to investigate the nonlinear interaction between the QTDW and planetary waves. Correlations between the mesospheric wind QTDW and the equatorial electrojet strength have been found by Gurubaran et al. (2001). Simulation results of Jacobi et al. (2006) suggest that tropospherically excited QTDW modulates gravity wave fluxes with the wave number and the period of the QTDW. In turn, the modulated gravity wave acceleration of the background circulation damps the QTDW in the mesosphere.

The excitation of the QTDW has been associated with two primary forcing mechanisms. The first mechanism associates the QTDW with the $(3,0)$ Rossby-gravity normal mode (Salby, 1981a, b). Salby (1981b) found that this normal mode had several features that are similar to the observations of the QTDW in the middle atmosphere, namely, its period is $\sim 2$ days, it is a westward propagating wave number 3 wave, and has an enhanced summer activity with the meridional component dominating its zonal counterpart. Further support for the relationship between the QTDW and the normal mode came from the numerical simulation of Hagan et al. (1993). Baroclinic instability of the easterly jet in the summer mesosphere has been proposed by Plumb (1983) as
Table 1. The abbreviations and geographic coordinates of the radars.

\begin{tabular}{lcrr}
\hline Site & Abbreviation & Longitude $\left(^{\circ}\right)$ & Latidude $\left(^{\circ}\right)$ \\
\hline Kodiak & KD & -152.19 & 57.62 \\
Prince George & PG & -122.59 & 53.98 \\
Saskatoon & SK & -106.53 & 52.16 \\
Kapuskasing & KP & -82.32 & 49.39 \\
Goose Bay & GB & -60.46 & 53.32 \\
Stokkseyri & ST & -22.02 & 63.86 \\
Pykkvibaer & PK & -30.54 & 63.77 \\
Hankasalmi & HK & 26.61 & 62.32 \\
\hline
\end{tabular}

the other possible excitation mechanism for the QTDW. Using a two-dimensional stability analysis, Pfister (1985) found peaks in the unstable wave growth spectrum in the $2-4$ zonal wave number range and a period range of 1.4-3 days. However, Pfister's baroclinically unstable waves were strongly trapped in the middle and high latitudes as opposed to the global nature seen in observations. Further numerical work on the instability excitation mechanism has been conducted by Merzlyakov and Jacobi (2004). They found a $\sim 2$-day oscillation with wave numbers 3 and 4 . The resulting wave subsequently removes the source of the instability. They found this effect to be sufficiently strong to reduce a strong jet and remove the negative gradient of the potential vorticity in the instability region. Randel (1994) suggested that the 2-day wave could be a combination of resonant and unstable modes, i.e. it is a near-resonant mode that is excited by baroclinic instability. This view was further supported by Salby and Callaghan (2001), who found that wave activity generated in the unstable region adjacent to the wave's critical line spreads globally into the Rossby-gravity modal structure.

In this paper we want to exploit the uniqueness of the Super Dual Radar Network (SuperDARN) in studying the QTDW. The SuperDARN consists of a chain of HF radars that are commonly used to measure electric fields and plasma drifts in the high-latitude ionosphere. However, they also detect backscatter from meteor trails at mesospheric heights and this capability can be exploited to study the QTDW and atmospheric tidal motion. These radars are ideally suited for the study of the longitudinal behaviour of the QTDW and the deduction of its zonal propagation characteristics. This is due to the fact that they cover a wide longitudinal band over a narrow latitudinal range. More specifically, the radars used here and whose details are given in Table 1 and whose fields-of-view are shown in Fig. 1, have a longitudinal coverage of $178.8^{\circ}$ and a relatively narrow latitude band of $14.47^{\circ}$, compared to the $54^{\circ}$ latitude range in the study by Pancheva et al. (2004). This makes them ideal to study longitudinally dependent features with minimum contamination from latitudinal effects. Another advantage with these 
radars is that they are primarily similar (technologically) and the data extraction processes are similar. This is an advantage over other studies which, although having a wider geographic coverage, tend to use data obtained using technologically different instruments (e.g. an MF radar and a meteor radar) and/or different retrieval methods.

\section{The SuperDARN and data acquisition}

The SuperDARN is a network of high frequency (HF) radars situated in the auroral zones of the Northern and Southern Hemispheres. These radars and their operation have been reviewed by Greenwald et al. (1995) and we only present a brief description here. The SuperDARN radars operate over a frequency range of $8-20 \mathrm{MHz}$. The main antennae of the radars consist of 16-log periodic antennas. The associated beam is electronically steered using time-delay phasing elements that point the beam in 16 directions covering a sector with a nominal azimuth of $52^{\circ}$. The azimuthal resolution is dependent on the operating frequency and ranges from $2.5^{\circ}$ at $20 \mathrm{MHz}$ and decreases to $6^{\circ}$ at $8 \mathrm{MHz}$. The transmitted pulses have typical lengths of $200-300 \mathrm{~ms}$, giving a range resolution of $30-40 \mathrm{~km}$. The radars are operated under different scan modes, examples of which can be found in Greenwald et al. (1995). The radars use various multipulse transmission sequences with 5-7 pulses that are transmitted over a 100-ms time interval. The backscattered returns from these pulses are sampled and then processed, giving multilag autocorrelation functions (ACFs). The ACFs are thereafter used to deduce backscattered power, the mean Doppler velocity and the width of the Doppler power spectrum for each range with significant returns.

The backscatter observed by the radars is primarily from plasma irregularities in the $E$ and $F$ regions of the ionosphere. Consequently, the SuperDARN radars are primarily used to study the behaviour of the plasma in the auroral oval, as well as the polar cap (Jenkins et al., 1998). However, Hall et al. (1997) have also identified near-range (ranges $<500 \mathrm{~km}$ ) echoes that have a "grainy" appearance. They referred to these echoes as "grainy near-range echoes" (GNRE) and attributed them to meteor trails. Subsequently, a number of meteor wind results using the SuperDARN have been reported. There has also been some comparison between SuperDARN wind results and those of the High Resolution Doppler Imager (HRDI) aboard the Upper Atmosphere Research Satellite (UARS) (Bristow et al., 1999), as well as with MF radar wind (Hussey et al., 2000). Bristow et al. (1999) found that both SuperDARN and HRDI observed a 2-day wave with wave number 3. However, the SuperDARN wave lagged that of the HRDI. Hussey et al. (2000) also found good comparison between wind measurements of the Hankasalmi $\left(62.3^{\circ} \mathrm{N}, 26.6^{\circ} \mathrm{E}\right)$ SuperDARN radar and those of the Troms $\varnothing \mathrm{MF}$ radar $\left(70^{\circ} \mathrm{N}, 19^{\circ} \mathrm{E}\right)$ in the meteor region.
The actual acquisition of the meteor region wind is accomplished by using data from the first several range gates of the radar. At these distances the transmissions have reached no higher than the mesosphere and the backscatter is due primarily to meteor trails. Due to the fact that our data does not have height resolution, we assume a nominal height of about $90-95 \mathrm{~km}$. Most meteors are observed at $\sim 90 \mathrm{~km}$ (e.g. Nakamura et al., 1991; Hocking et al., 2001). Hourly wind averages are computed for each beam direction giving a lineof-sight wind velocity. The mean zonal and meridional velocity estimates are thereafter evaluated using a least-squares fitting.

\section{Results}

\subsection{Spectral characteristics of the QTDW}

In our analysis we have used data for the year 2002 for the SuperDARN radars specified in Table 1. The fields-of-view of the radars are shown in Fig. 1. As the name suggests, the period of the quasi-two-day wave is not one discrete period, therefore it is always necessary to first determine the dominant spectral components within the frequency band of interest. To do this we have performed a dynamic Fourier spectra using a 28-day data window which is shifted forward by 1 day at a time. The power deduced for a given data window was attributed to a "central day" given by day 14 of that particular 28-day data interval. This relatively long data window results in the desired frequency resolution of 0.0357 cycles per day (cpd), giving us 7 frequency samples in the $39-60 \mathrm{~h}$ period band. However, the problem is that this frequency resolution is at the expense of time resolution. This is particularly serious because the QTDW is characterised by bursts of wave activity that are variable on scales of several days (e.g. Pancheva et al., 2004). This, of course, means that taking a long data window compromises the spectral amplitudes. Nonetheless, for the purpose of deducing the average spectral content in the 39-60 h period band, the 28-day data window is a suitable compromise and has been used where appropriate in this paper.

The results of the dynamic spectra are shown in Fig. 2 for the meridional component. In this figure, and several others that follow, individual panels are used for different radars, as indicated by corresponding abbreviations (see Table 1). Here we have only plotted the normalised power spectra for the summer season (1 June-31 August) because the QTDW is stronger during this time (see Figs. 3 and 4). The black contours indicate the $95 \%$ confidence level using a chi-square test, assuming white noise as the background spectrum (e.g. Torrence and Compo, 1998). The power has been normalised by $\sigma^{2} / N$, where $N$ is the number of the data points and $\sigma^{2}$ is the variance of the time series. For both the meridional flow and the zonal flow (not shown), the dominant spectral component has a period of $\sim 48 \mathrm{~h}$ with another strong peak 
Table 2. The correlation coefficients of the normalised power spectrum of the 42-, 48- and 52-h for the summer duration, for the zonal and the meridional components.

\begin{tabular}{lccrrrrrrrr}
\hline & $\mathrm{T}_{1}(\mathrm{~h})$ & $\mathrm{T}_{2}(\mathrm{~h})$ & $\mathrm{KD}$ & $\mathrm{PG}$ & $\mathrm{SK}$ & $\mathrm{KP}$ & $\mathrm{GB}$ & $\mathrm{ST}$ & $\mathrm{PK}$ & $\mathrm{HK}$ \\
\hline \multirow{4}{*}{ Zonal } & 42 & 48 & 0.8 & 0.9 & 0.6 & 0.2 & 0.6 & 0.7 & \\
& 42 & 52 & -0.4 & -0.2 & 0.2 & -0.1 & -0.4 & -0.4 & \\
& 48 & 52 & -0.2 & -0.4 & 0.3 & 0.1 & -0.2 & -0.2 & \\
\hline \multirow{4}{*}{ Meridional } & 42 & 48 & 0.7 & 0.4 & 0.7 & -0.2 & & 0.0 & 0.1 & \\
& 42 & 52 & -0.3 & -0.5 & -0.3 & -0.5 & 0.3 & -0.2 & \\
& 48 & 52 & 0.0 & 0.1 & -0.4 & 0.3 & -0.3 & -0.4 & \\
\hline
\end{tabular}

MERIDIONAL FLOW: Normalised power spectrum (28d window)
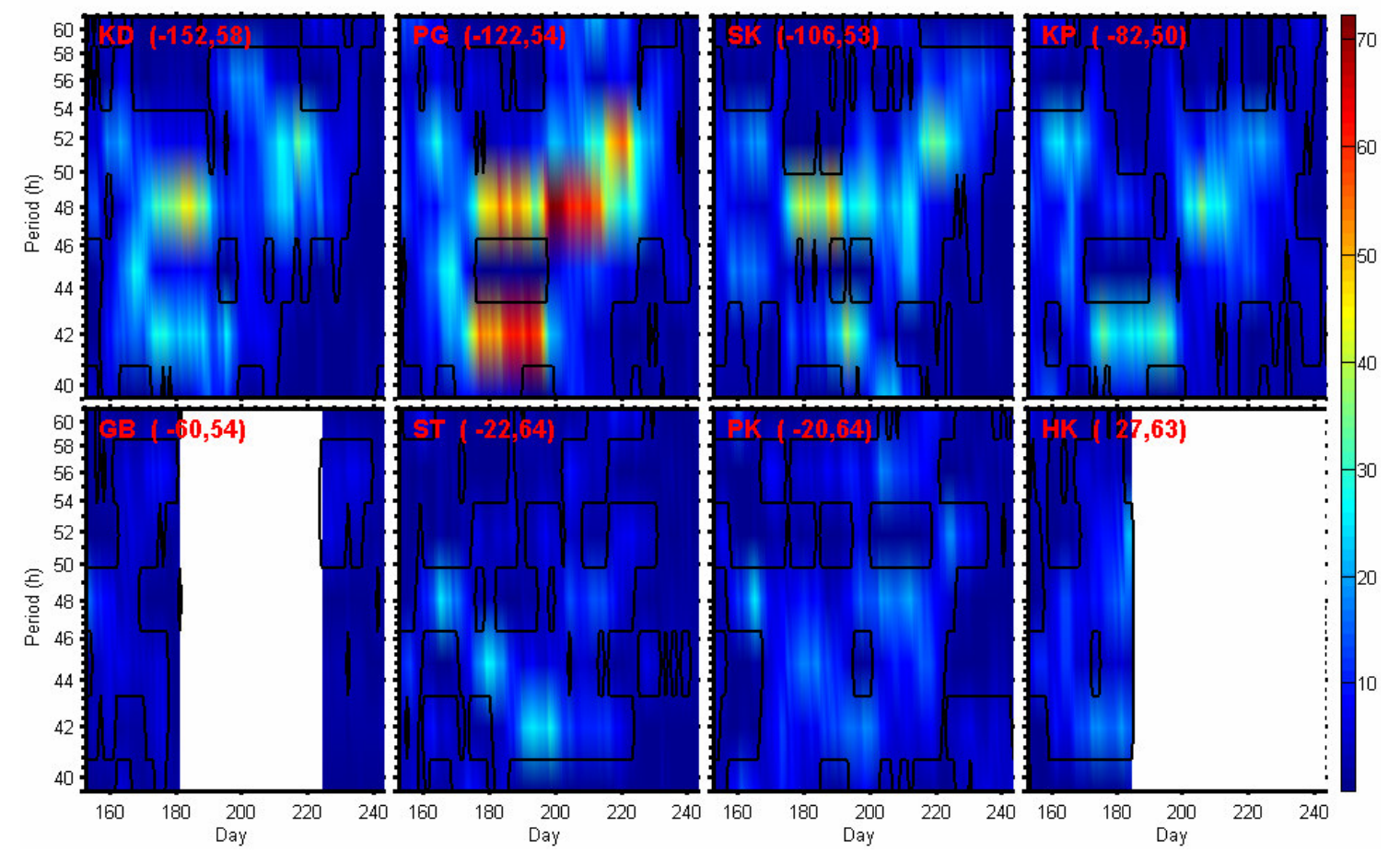

Fig. 2. The normalised power spectrum for the meridional flow in summer for different radars, as indicated by the abbreviations on the top left-hand corner of each panel. The black contours represent the $95 \%$ confidence levels.

at $\sim 42 \mathrm{~h}$ and to some extent some power at $\sim 52 \mathrm{~h}$. Sometimes the $42 \mathrm{~h}$ component is even stronger than the $48-\mathrm{h}$ component. There is also evidence of other spectral components with periods of about $44-\mathrm{h}, 52-56 \mathrm{~h}$. There are times when the frequencies of the dominant components exhibit a systematic change with time.

\subsection{QTDW spectra for $\sim 42-, \sim 48$ - and $\sim 52$-h components}

Having established that the dominant spectral components have periods of $\sim 42-, \sim 48$ and $\sim 52$-h, we did a detailed study of these three spectral components. In Figs. 3 and 4 we have plotted the normalised Fourier power spectra of the
QTDW for the zonal and the meridional components, respectively. The horizontal line represents the $95 \%$ confidence level. From the figures it is clear that the meridional and the zonal QTDW have a seasonal pattern characterised by enhanced wave activity in summer superimposed on shortterm fluctuations. We observe bursts of wave activity from around day 120 to around day 240 , which is close to the summer season (June to August, i.e. days 152 to 243). The summer activity tends to be above the $95 \%$ confidence level and Prince George has the strongest activity followed by the neighbouring stations of Kodiak and Saskatoon. Stokkseyri also has amplified activity for the zonal 42-h component. The summer normalised power peaks can be as large as $\sim 70$ 


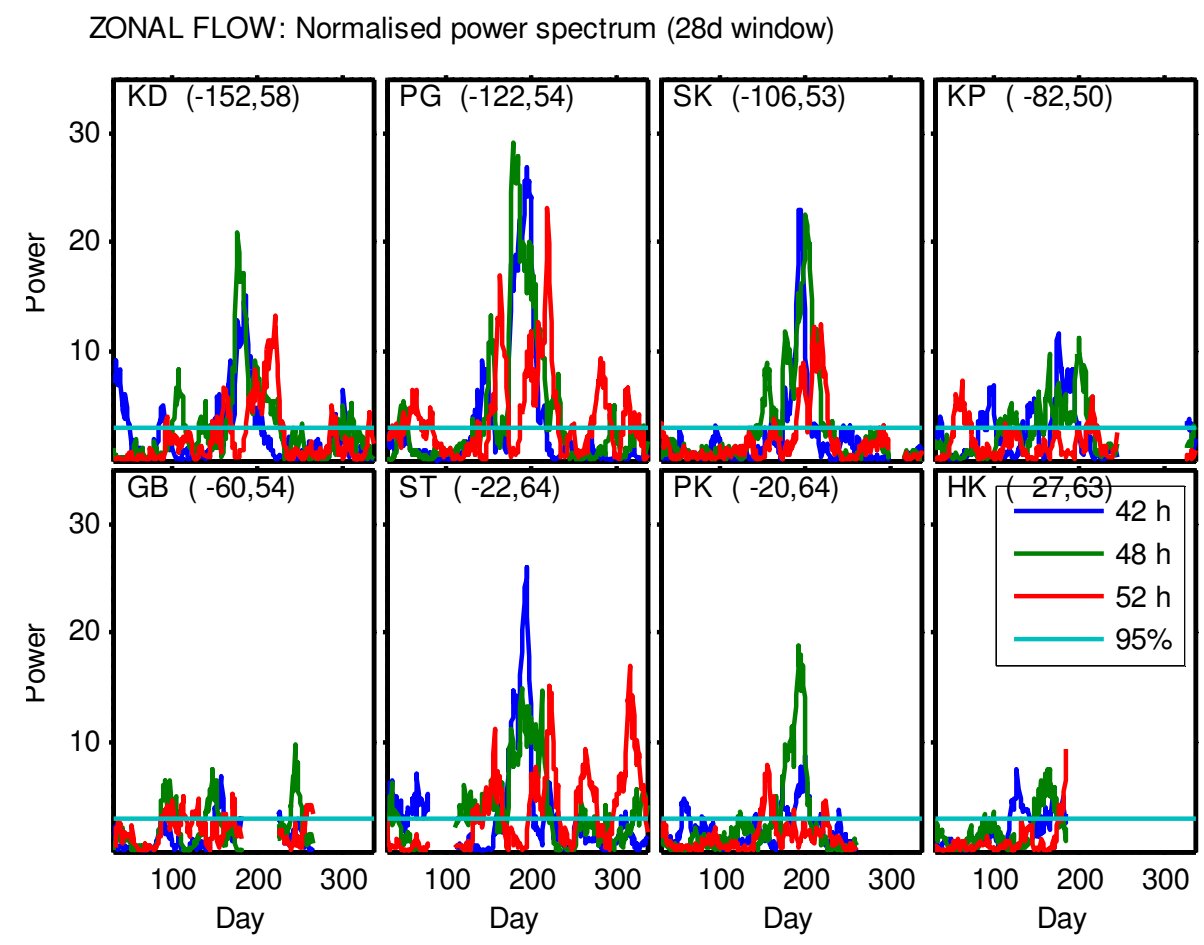

Fig. 3. The normalised power spectrum of the zonal 42-, 48- and 52-h QTDW components for different radars, as indicated by the abbreviations on the top left-hand corner of each panel. The horizontal line represents the $95 \%$ confidence level.

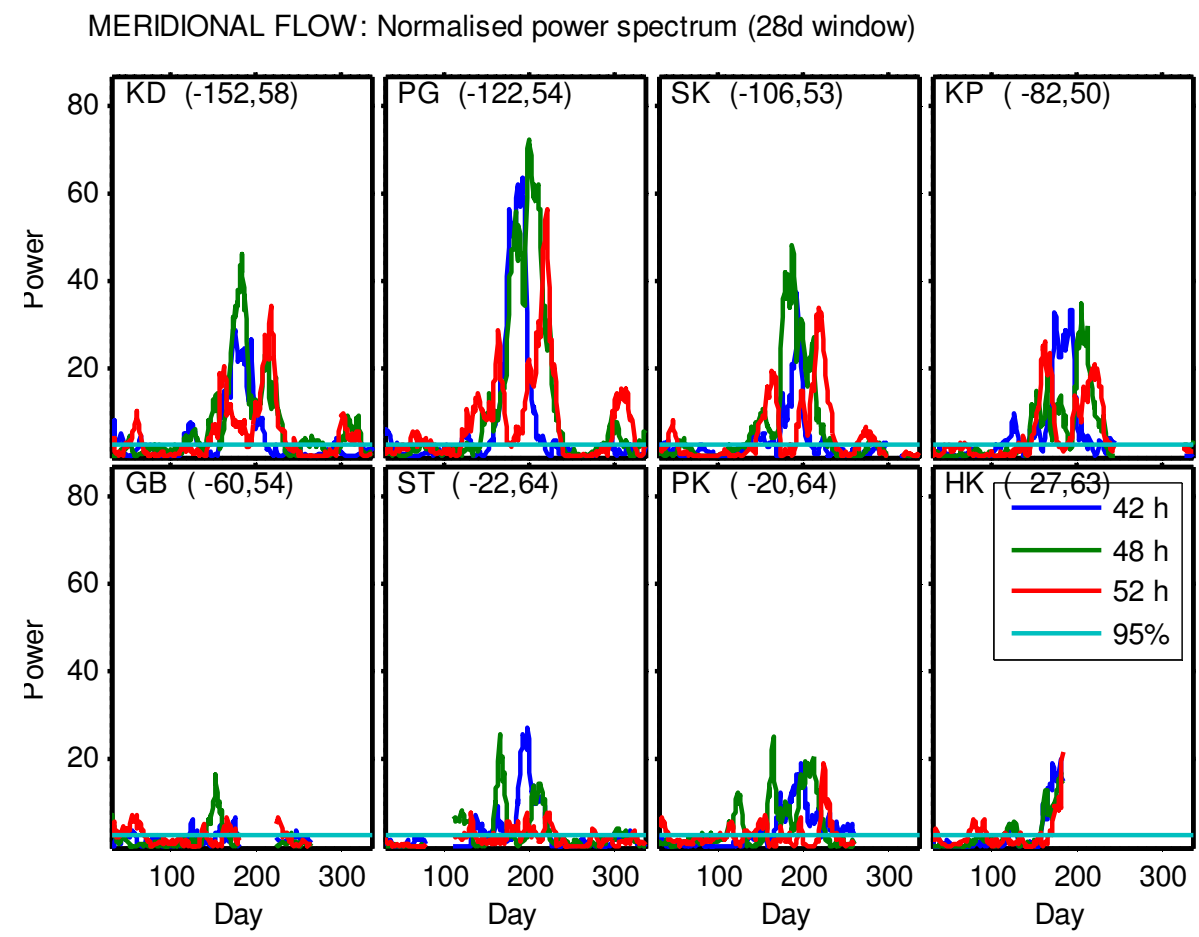

Fig. 4. The normalised power spectrum of the meridional 42-, 48- and 52-h QTDW components for different radars, as indicated by the abbreviations on the top left-hand corner of each panel. The horizontal line represents the $95 \%$ confidence level. 
2002 MERIDIONAL POWER \& ZONAL MEAN FLOW: Wave power. Black; Mean flow $\left(\mathrm{U}_{0}\right)$
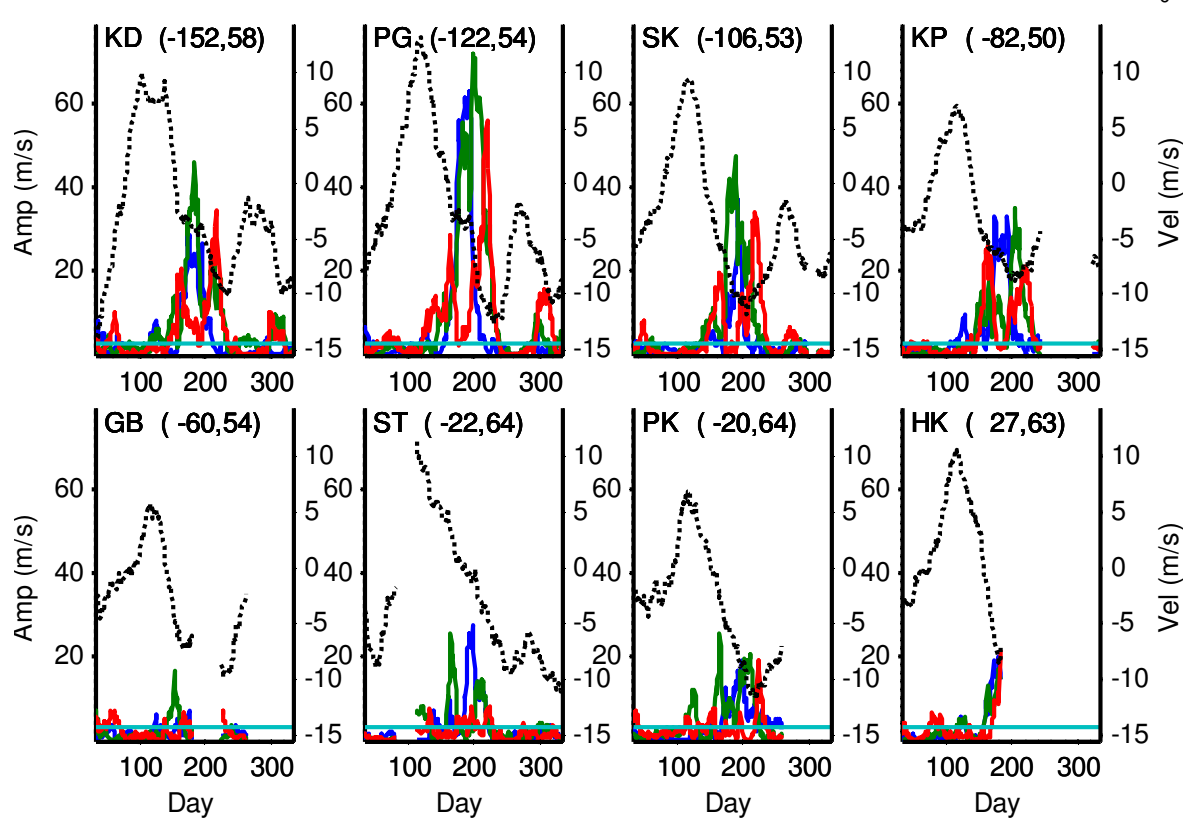

Fig. 5. The normalised power spectrum of the meridional 42-h (blue), 48-h (green) and 52-h (red) QTDW components and the zonal mean flow (dotted) for different radars, as indicated by the abbreviations on the top left-hand corner of each panel. The horizontal line represents the $95 \%$ confidence level.

(meridional) and $\sim 30$ (zonal). With the exception of Goose Bay and Hankasalmi (which have missing data during the summer season), the amplified summer activity in the QTDW (zonal and meridional) extends over all sites for the 42- and the 48-h components, albeit with varying strength for the different sites. The 52-h component, on the other hand, does not show a distinct summer peaking for some sites, e.g. the meridional component at Stokkseyri and Pykkvibaer. However, this spectral component can also show some extended burst of activity stretching throughout most of the second half of the year with evidence of planetary scale modulation (e.g. zonal component at Stokkseyri and to some extent Prince George). The figures show that for a number of sites, especially those with strong wave activity, the 42 - and the 48 -h components tend to coincide giving high correlation values in Table 2. The 52-h component is relatively weaker than the other two components but can have comparable strength at times. On average, the 52-h component activity is negatively correlated to the 42- and the 48-h components (Table 2). In general, the meridional component is slightly stronger than its zonal counterpart and this is in line with simulations (Palo et al., 1999).

\subsection{The QTDW power and the mean flow}

In Figs. 5 and 6 we investigate the correlation between the meridional power spectra and the zonal and meridional mean flow, respectively. Here we have omitted the zonal power of the QTDW because, as observed in Fig. 3, its seasonal trend is largely similar to that of the meridional component (Fig. 4). Figure 5 shows that, in general, the onset of amplified wave activity in meridional power coincides with the beginning of the westward acceleration of the zonal mean flow around day 120. This is in line with the findings of Plumb et al. (1987) and Gurubaran et al. (2001). Our results also show that meridional power enhancement tends to correspond with strong southward meridional mean flow (Fig. 6). However, the equatorward acceleration of the meridional mean flow starts much earlier than the wave amplification. The TIMEGCM simulation results of Palo et al. (1999) show both eastward and westward acceleration for the zonal flow and northward and southward acceleration for the meridional mean flow. Their acceleration patterns show eastward/westward and northward/southward acceleration bands that alternate with height. If this is true for the region we are studying here, it might have negative effects on our results because we do not have height resolution.

\subsection{QTDP period}

We determined the instantaneous period via the analytic signal method using the algorithm described by Suzuki et al. (2006). This was accomplished by first Fourier transforming the mean-corrected time series and then setting the negative and dc components to zero, in order to obtain the analytic signal. Thereafter, a bandpass filter with a period passband 
2002 MERIDIONAL POWER \& MERIDIONAL MEAN FLOW: Wave power. Black; Mean flo

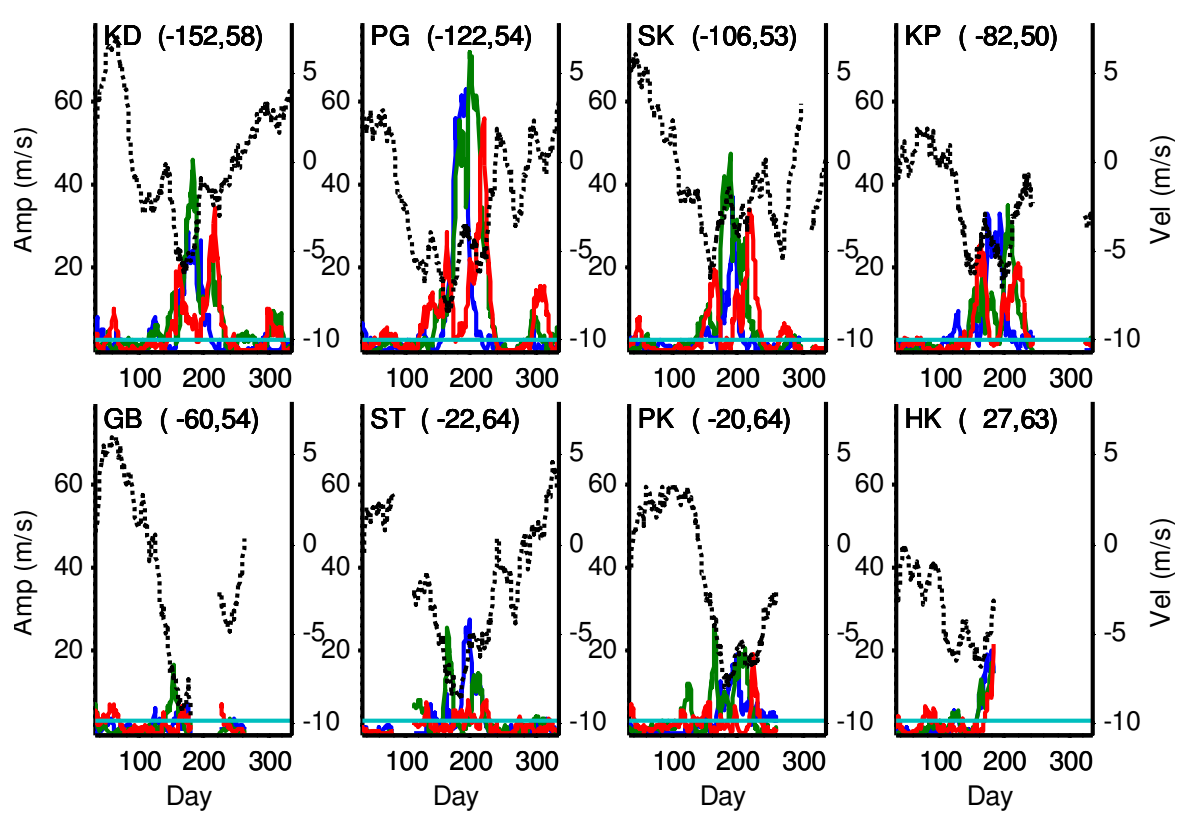

Fig. 6. The normalised power spectrum of the meridional 42-h (blue), 48-h (green) and 52-h (red) QTDW components and the meridional mean flow (dotted) for different radars, as indicated by the abbreviations on the top left-hand corner of each panel. The horizontal line represents the $95 \%$ confidence level.

of 30-60 h was applied after which the result was inverse Fourier transformed. The magnitude and argument of the resultant complex series gives the instantaneous hourly amplitude $A(t)$ (with a scaling of 0.5 ) and instantaneous hourly phase $\phi(t)$, respectively. The instantaneous hourly frequency was then calculated according to $f(t)=(1 / 2 \pi) d \phi(t) / d t$, from which the instantaneous hourly period $T(t)$ was deduced. For this analysis we used a 15-day long time window and only the instantaneous hourly amplitudes and periods of the "central day" of the interval (i.e. day 8) were stored, thus minimising the edge effects (Suzuki et al., 2006). The 15-day interval is thereafter advanced by one day and the process repeated. Overall, the analysis was done such that the "central days" for which the instantaneous amplitudes and periods were extracted fell within the summer season (1 June to 31 August). As seen in Figs. 3 and 4 the summer season tends to have spectral power that is mostly above the $95 \%$ confidence level, giving credibility to the instantaneous periods deduced here. Further, the histograms (Fig. 7) only include instantaneous periods for which the corresponding instantaneous amplitudes were above the average instantaneous amplitude for all the sites with data. For the meridional flow this multisite average is $7.7 \pm 1.0 \mathrm{~m} / \mathrm{s}$. From the figure the most frequent periods (within a $30-60 \mathrm{~h}$ period passband) are in the range $40-50 \mathrm{~h}$ with site averages of $\sim 42-45 \mathrm{~h}$. This is in line with the fact that the 42-h and the 48-h components tend to be highly correlated (Table 2 and Fig. 4) and are of comparable magnitude. A time series with two components of equal amplitudes has an instantaneous frequency which is equal to the average of the frequencies of the constituent components (Suzuki et al., 2006).

Going back to Fig. 2 we observe that there are times when the frequencies of the dominant components exhibit a systematic change with time. For instance, the meridional component at Prince George and Saskatoon starts off with a period of $\sim 48 \mathrm{~h}$ around day 175 and progresses to a period of $\sim 50$ or $52 \mathrm{~h}$ by day 210 . It has been pointed out by Hagan et al. (1993) that the intrinsic wave frequency $\tilde{\sigma}$ is related to the true wave frequency $\sigma$ by

$\tilde{\sigma}=\sigma+\frac{s U}{a \sin \theta}$

where $s$ is the zonal wave number and, $U$ is the zonal mean wind, $a$ is the mean radius of the Earth, and $\theta$ is the colatitude. Therefore, the systematic change in period could be due to a change in the zonal mean flow and the zonal wave number. Differences in zonal mean wind fields have been found to cause a shift in the resonance period of the QTDW (Hagan et al., 1993).

\subsection{Zonal wave number}

Figures $8 \mathrm{a}$ and $\mathrm{b}$ show the zonal wave number for the zonal and the meridional components, respectively. The zonal wave numbers were derived from the slope of the linear regression of the QTDW phase as a function of longitude. For this analysis we used the phases obtained from the 28-day 


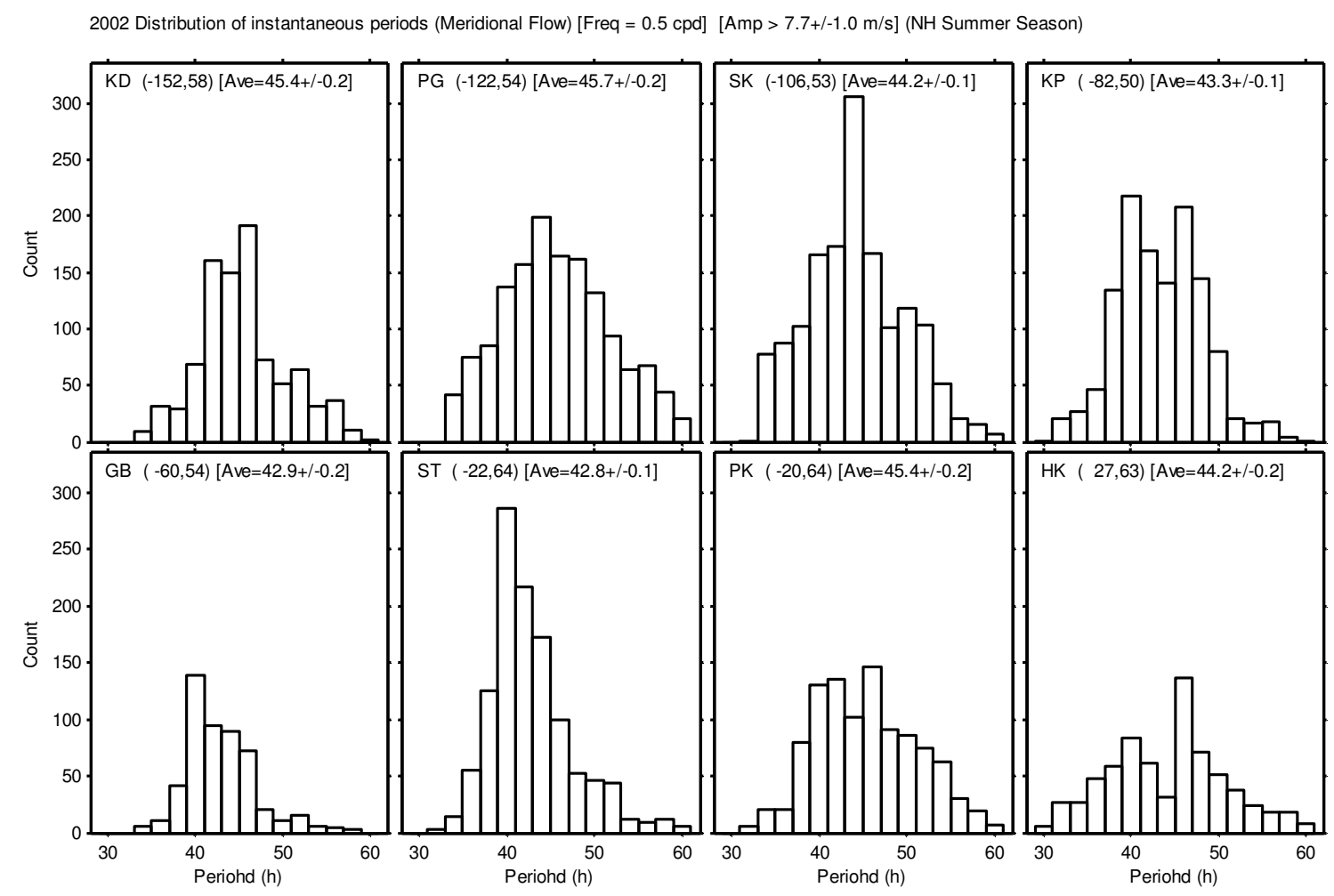

Fig. 7. Distribution of the instantaneous hourly periods of the QTDW for the meridional flow in summer for different radars, as indicated by the abbreviations on the top left-hand corner of each panel.

Fourier spectral analysis described in Sect. 3.1 because we wanted to use phases that are well resolved in frequency. The phases used here are those for the "central days" which fall within the summer season a time at which the spectral power tends to be above the 95\% confidence level (Figs. 3 and 4). The wave number was deduced for each "central day", taking into consideration the phases for the 8 sites considered here, depending on data availability. In Fig. 8 we have only used wave numbers for which at least 4 sites had data and the coefficient of determination was $70 \%$. For our results negative wave numbers represent a westward propagating wave. For the zonal component, the zonal wave number $s=-3$ tends to dominate, especially for the 48-h component while the 42-h and the 52-h components also show some presence of a zonal wave number $s=-2$. For the meridional flow there is a strong presence of the $s=-4$ and -3 for the 48 -h component. The 42 -h component is dominated by $s=-2,-4$ and -1 , in that order, while the 52 -h component is dominated by $s=-1$.

Figure 9 shows the wave number spectrum overlaid on the cross-amplitude spectrum from a Prince George-Kodiak Fourier cross-spectral analysis (Fig. 9a). A similar analysis is shown in Fig. 9b for Prince George and Saskatoon with Fig. 9c showing the average of Figs. 9a and b. These three sites were chosen because of data availability and the relatively larger wave power measured at these sites. And once again we have restricted our analysis to the summer season, which has wave activity that is frequently above the $95 \%$ confidence level. Figure 9 indicates that in the neighbourhood of the period of $48 \mathrm{~h}$, the amplitudes are more pronounced and this tends to coincide with less variable wave number structures that are slowly altering between -2 to -4 . A less variable wave number structure is again observed during amplified wave activity around a period of $42 \mathrm{~h}$ for days around 170-200. Otherwise, the wave number structure is variable during periods of weak wave activity.

\section{Discussion}

The QTDW is global-scale wave that has been observed in both hemispheres. In this work we have used the longitudinal spread of the SuperDARN radars to study its behaviour in the Northern Hemisphere auroral zone for the year 2002. Altogether data from 8 radar sites with a longitudinal coverage of $178.8^{\circ}$ and a latitude band of $14.47^{\circ}$ were used. While the wide longitudinal coverage over a relatively narrow latitudinal range is advantageous in studying the zonal structure of the wave, the lack of height resolution in our data is a limitation. We have assumed a nominal height corresponding to the peak of the meteor region $(\sim 90-95 \mathrm{~km})$. The dynamic spectra shows that the wind field in the $40-60 \mathrm{~h}$ band is dominated by components with periods of $\sim 42-, \sim 48$ - and $\sim 52$-h 

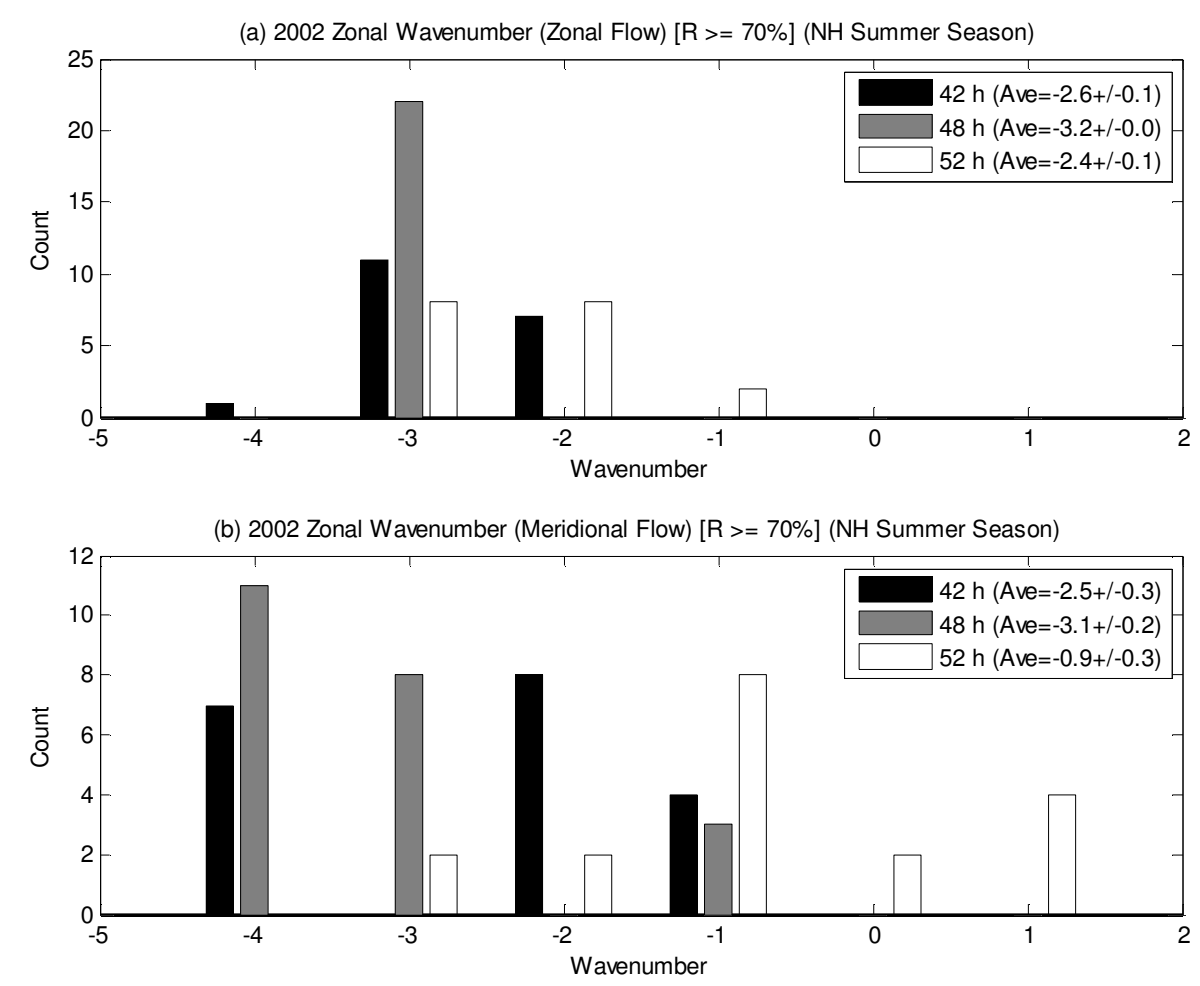

Fig. 8. The distribution of the zonal wave number for the zonal and the meridional 42-, 48- and 52-h QTDW components in summer. Negative represents westward propagating waves.

whose strength varies with time and location. The three components above were extracted and studied in detail and they exhibit a seasonal behaviour characterised by enhanced wave activity in summer, with a greater correlation between the 42 and the 48 -h components. The 52-h component is generally weaker and tends to be negatively correlated to the 42 - and to the 48-h component. While the lack of height resolution could be compromising our amplitudes, the effect should not be severe because the wave tends to have long vertical wavelengths $(>150 \mathrm{~km})$ or evanescent behaviour during enhanced wave activity (Thayaparan et al., 1997a). However, in some cases the wavelengths can also be in the range of $25-100 \mathrm{~km}$ (Palo and Avery, 1996; Gurubaran et al., 2001; Lima et al., 2004).

The summer enhancement could be linked to baroclinic instabilities. Randel (1994) found that enhanced wave activity coincided with near-zero or negative potential vorticity, linking the excitation of the QTDW to the instability of the summer easterly jet. At the same time, his overall observations showed a meridional and vertical structure of the 2-day wave that is consistent with the normal mode calculations of Salby (1981a, b). Based on these two results, Randel (1994) suggested that the 2-day wave could be a combination of resonant and unstable modes i.e. it is a near-resonant mode that is excited by baroclinic instability. Salby and Callaghan (2001) conducted simulations that revealed that the structure and growth of the $(3,0)$ mode obtains auxiliary forcing from the instability during the solstice. They found that wave activity generated in the unstable region adjacent to the wave's critical line spreads globally into the Rossby-gravity modal structure. The amplification of the Rossby-gravity normal mode through the interaction with the easterlies is responsible for the twice-a-year amplification of the 2-day wave (Salby and Callaghan, 2001). The peak amplitude of the QTDW increases with the strength of the instability while the period of the strongest component is inversely proportional to the strength of the instability (Merzlyakov and Jacobi, 2004).

In general, we found that the onset of amplified wave activity in meridional power coincides with the beginning of the westward acceleration of the zonal mean flow. This is in line with the findings of Plumb et al. (1987) and Gurubaran et al. (2001). Our results also show that the meridional power enhancement tends to correspond with a strong southward meridional mean flow and the associated equatorward acceleration of the meridional mean flow starts much earlier than the QTDW enhancement. Merzlyakov and Jacobi (2004) pointed out that changes in the climatological background atmosphere may cause instability in the mean zonal wind distribution. This instability generates a 2-day wave with zonal wave numbers 3 and 4 . The excitation and propagation of these waves, in turn, lead to changes in the mean zonal distribution of the zonal wind. 


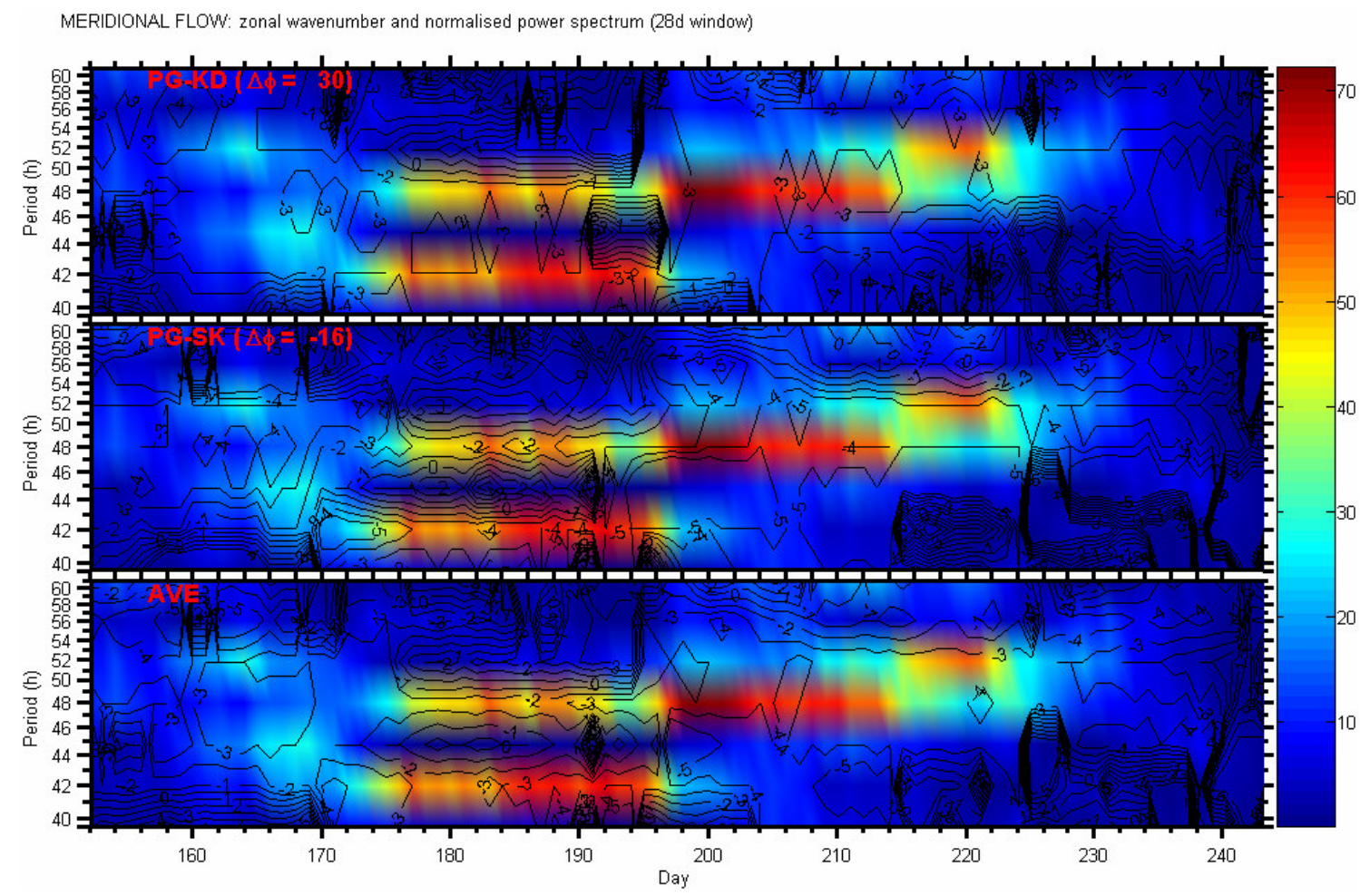

Fig. 9. (a) The zonal wave number spectrum overlaid on the cross-spectral amplitude of the wave (colour) for PG-KD cross-spectral analysis. (b) Same as (a) but for PG-SK analysis. (c) Average of (a) and (b). (Same as the previous version) $\Delta \phi$ represents the longitudinal separation between the sites.

The instantaneous hourly period obtained by the analytic signal method is frequently between $42-\mathrm{h}$ and $48-\mathrm{h}$. Since these two spectral components are highly correlated in summer and have comparable amplitudes, the instantaneous period would tend to be the average of the periods of the two components (Suzuki et al., 2006). The 42-, 48- and 52-h in summer have a wide ( $s=-4$ to $s=1)$ zonal wave number spectrum. The 48-h component is dominated by the $s=-3$ and -4 while the 42 -h is dominated by wave numbers $s=-2$, -3 and -4 . According to Lieberman (1999), the QTDW is a wave "packet" that consists of zonal wave numbers -2 , $-3,-4$ and periods $3.5,2.1,1.7$ days (i.e. 84-, 50.4, 40.8h), respectively. Merzlyakov and Jacobi (2004) found waves with zonal wave number $s=3$ and 4 that have comparable peak amplitudes and reach their maxima at different times. In addition, the latter wave tends to be relatively localised to its source region in latitude. By increasing the excitation height, these authors found that the $s=4$ component tends to dominate the $s=3$ component. The wide spectrum of wave numbers observed in our results is possibly due to nonlinear interactions between tides and/or planetary waves with the QTDW. For instance, Palo et al. (1999) found that an eastward $(s=+2)$ wave was produced by the non-linear interaction of the diurnal tide $(1,-1)$ and the QTDW $(0.5$, -3). Similarly, Merzlyakov and Jacobi (2004) found that through nonlinear interactions between planetary waves (12day wave) and the $s=4$ component there is a transfer of energy from the latter component to an unstable $s=3$ QTDW wave with a period of $\sim 56 \mathrm{~h}$. This $s=3$ wave decouples to $s=1$ and $s=2$ which have longer periods $(\sim 100-150 \mathrm{~h})$.

The wide spectrum of zonal wave numbers that we observe could result in a nonuniformity in QTDW activity with longitude. This may account of the difference in the spectral power as observed in our results. More specifically, Figs. 2 to 4 show longitudinal differences in the strength of the QTDW, with Prince George having the strongest wave activity followed by Kodiak and Saskatoon. It should be pointed out though that these differences could also be aggravated by latitudinal differences which can be as large as 50\% (Pancheva et al., 2004).

Broadly, our results are consistent with results reported elsewhere and agree well with the typical behaviour of the QTDW but it should be noted that we only considered data for 2002. Considering the fact that there could be interannual differences, as alluded to by Hagan et al. (1993), more work still needs to be done involving more data. Also it is worth noting that the mesospheric wind field in the northern summer of 2002 deviated from typical behaviour and was characterised by weaker mean zonal and meridional winds (Singer et al., 2005), larger gravity wave amplitudes, lower 
temperatures, and a more stable temperature gradient (Rapp et al., 2004). Therefore, one would expect an extended analysis covering more years, as planned for the future, to yield slightly different results. It would also be interesting to extend the investigation to Southern Hemisphere SuperDARN sites and particularly look at inter-hemispheric effects.

Acknowledgements. This material is based upon work supported by the National Research Foundation (NRF), and the University of KwaZulu-Natal. The SuperDARN radars in the Northern Hemisphere are supported by the funding agencies of the U.S., Canada, the UK, France, and Japan. The authors would also like to thank the SuperDARN Principal Investigators for the data used in this study. Any opinion, findings and conclusions or recommendations expressed in this material are those of the authors and therefore the NRF and the other sponsors do not accept any liability thereto.

Topical Editor U.-P. Hoppe thanks two anonymous referees for their help in evaluating this paper.

\section{References}

Bristow, W. A., Yee, J.-H., Zhu, X., and Greenwald, R. A.: Simultaneous observations of the July 1996 2-day wave event using the Super Dual Auroral Radar Network and the High Resolution Doppler Imager, J. Geophys. Res., 104, 12 715-12 721, 1999.

Greenwald, R. A., Baker, K. B., Dudeney, J. R., Pinnock, M., Jones, T. B., Thomas, E. C., Villain, J.-P., Cerisier, J.-C, Senior, C., Hanuise, C., Hunsucker, R. D., Sofko, G., Koehler, J., Nielsen, E., Pellinen, R., Walker, A. D. M., Sato, N., and Yamagishi, H.: DARN/SuperDARN: A global view of the dynamics of highlatitude convection, Space Sci. Rev., 71, 761-796, 1995.

Gurubaran, S., Sridharan, S., Ramkumar, T. K., and Rajaram, R.: The mesospheric quasi-2-day wave over Tirunelveli $\left(8.7^{\circ} \mathrm{N}\right)$, J. Atmos. Solar-Terr. Phys., 63, 975-985, 2001.

Hagan, M. E., Forbes, J. M., and Vial, F.: Numerical investigation of the propagation of the quasi-two-day wave into the lower thermosphere, J. Geophys. Res., 98, 23 193-23 205, 1993.

Hall, G. E., MacDougall, J. W., Moorcroft, D. R., and St.-Maurice, J.-P.: Super Dual Auroral Radar Network observations of meteor echoes, J. Geophys. Res., 102, 14 603-14 614, 1997.

Hocking, W. K., Fuller, B., and Vandepeer, B.: Real-time determination of meteor-related parameters utilizing modern digital technology, J. Atmos. Solar-Terr. Phys., 63, 155-169, 2001.

Hussey G. C., Meek, C. E., André, D., Manson, A. H., Sofko, G. J., and Hall, C. M.: A comparison of northern hemisphere winds using SuperDARN meteor trail and MF radar wind measurements, J. Geophys. Res., 105, 18 053-18 066, 2000.

Jacobi, Ch., Schminder, R., and Kürschner, D: The quasi 2-day wave as seen from D1 LF wind measurements over Central Europe $\left(52^{\circ} \mathrm{N}, 15^{\circ} \mathrm{E}\right)$ at Collm, J. Atmos. Solar-Terr. Phys., 59, 1277-1286, 1997.

Jacobi, Ch., Schminder, R., and Kürschner, D.: Non-linear interaction of the quasi 2-day wave and long-term oscillations in the summer midlatitude mesopause region as seen from LF D1 wind measurements over Central Europe $\left(\right.$ Collm, $\left.52^{\circ} \mathrm{N}, 15^{\circ} \mathrm{E}\right)$, J. Atmos. Solar-Terr. Phys., 60, 1175-1191, 1998.

Jacobi, C., Fröhlich, K., and Pogoreltsev, A.: Quasi two-day-wave modulation of gravity wave flux and consequences for the plan- etary wave propagation in simple circulation model, J. Atmos. Solar-Terr. Phys., 68, 283-292, 2006.

Jenkins, B., Jarvis, M. J., and Forbes, D. M.: Mesospheric wind observations derived from Super Dual Auroral Radar Network (SuperDARN) HF radar meteor echoes at Halley, Antarctica: Preliminary results, Radio Sci., 33, 957-965, 1998.

Lieberman, R. S.: Eliassen-Palm fluxes of the 2-day wave, J. Atmos. Sci., 56, 2846-2861, 1999.

Lima, L. M., Batista, P. P., Takahashi, H., and Clemesha, B. R.: Quasi-two-day wave observed by meteor radar at $22^{\circ} \mathrm{S}$, J. Atmos. Solar-Terr. Phys., 66, 529-537, 2004.

Merzlyakov, E. G. and Jacobi, Ch.: Quasi-two-day wave in an unstable summer atmosphere - some numerical results on excitation and propagation, Ann. Geophys., 22, 1917-1929, 2004, http://www.ann-geophys.net/22/1917/2004/.

Nakamura, T., Tsuda, T., and Tsutsumi, M.: Meteor wind observations with the MU radar, Radio Sci., 26, 857-869, 1991.

Palo, S. E. and Avery, S. K.: Observations of the quasi-two-day wave in the middle and lower atmosphere over Christmas Island, J. Geophys. Res., 101, 12 833-12 846, 1996.

Palo, S. E., Roble, R. G., and Hagan, M. E.: Middle atmosphere effects of the quasi-two-day wave determined from a General Circulation Model, Earth Planets Space, 51, 629-647, 1999.

Pancheva, D., Mitchell, N. J., Manson, A. H., Meek, C. E., Jacobi, Ch., Portnyagin, Yu., Merzlyakov, E., Hocking, W. K., MacDougall, J., Singer, W., Igarashi, K., Clark, R. R., Riggin, D. M., Frenke, S. J., Kürschener, D., Fahrutdinova, A. N., Stepanov, A. M., Kashcheyev, B. L., Oleynikov, A. N., and Muller, H. G.: Variability of the quasi-2-day wave observed in the MLT region during the PSMOS campaign of June-August 1999, J. Atmos. Solar-Terr. Phys., 66, 539-565, 2004.

Pancheva, D. V.: Quasi-2-day wave and tidal variability observed over Ascension Island during January/February 2003, J. Atmos. Solar-Terr. Phys., 68, 390-407, 2006.

Pfister, L.: Baroclinic instability of easterly jets with applications to the summer mesosphere, J. Atmos. Sci., 42, 313-330, 1985.

Plumb, R. A.: Baroclinic instability of the summer mesosphere: a mechanism for the quasi-two-day wave?, J. Atmos. Sci., 40, 262-270, 1983.

Plumb, R. A., Vincent, R. A., and Graig, R. L.: The quasi-two-day wave event of January 1984 and its impact on the mean mesospheric circulation, J. Atmos. Sci., 44, 3030-3036, 1987.

Randel, W. J.: Observations of the 2-day wave in NMC stratospheric analyses, J. Atmos. Sci., 51, 306-313, 1994.

Rapp, M., Strelnikov, B., Müllemann, A., Lübken, F.-J., and Fritts, D. C.: Turbulence measurements and implications for gravity wave dissipation during the MaCWAVE/MIDAS rocket program, Geophys. Res. Lett., 31, L24S07, doi:10.1029/2003GL019325, 2004.

Salby, M. L.: Rossby normal modes in nonuniform background configurations. Part I: Simple fields, J. Atmos. Sci., 38, 18031826, 1981a.

Salby, M. L.: Rossby normal modes in nonuniform background configurations. Part II: Equinox and solstice conditions, J. Atmos. Sci., 38, 1827-1840, 1981b.

Salby, M. L. and Callaghan, P. F.: Seasonal amplification of the 2day wave: relationship between normal mode and instability, J. Atmos. Sci., 58, 1858-1869, 2001.

Singer, W., Latteck, R., Hoffman, P., Williams, B. P., Fritts, D. C., 
Murayama, Y., and Sakanoi, K.: Tides near the Arctic summer mesospause during the MaCWAVE/MIDAS summer program, Geophys. Res. Lett., 32, L07S90, doi:10.1029/2004GL021607, 2005.

Suzuki, H., Ma, F., Izumi, H., Yamazaki, O., Okawa, S., and Kido, K.: Instantaneous frequencies of signals obtained by the analytic signal method, Acoust., Sci. Technol., 27, 163-170, 2006.

Thayaparan, T., Hocking W. K., and MacDougall, J.: Amplitude, phase, and period variations of the quasi 2-day wave in the mesosphere and lower thermosphere over London, Canada, during 1993 and 1994, J. Geophys. Res., 102, 9461-9478, 1997a.
Thayaparan, T., Hocking W. K., MacDougall, J., Manson, A. H., and Meek, C. E.: Simultaneous observations of the 2-day wave at London and Saskatoon near $91 \mathrm{~km}$ altitude during the two years 1993 and 1994, Ann. Geophys., 15, 1324-1339, 1997 b.

Torrence, C. and Compo, G. P.: A practical guide to wavelet analysis, Bull. Am. Meteor. Soc., 79, 61-78, 1998.

Wu, D. L., Hays, P. B., Skinner, W. R., Marshall, A. R., Burrage, M. D., Lieberman, R. S., and Ortland, D. A.: Observations of the quasi 2-day wave from the high-resolution Doppler imager on UARS, Geophys. Res. Lett., 20, 2853-2856, 1993. 